\title{
LEI 13.467/2017: ANÁLISE DO PRINCÍPIO DA INTERVENÇÃO MÍNIMA À LUZ DA ORDEM ECONÔMICA E SOCIAL DA CONSTITUIÇÃO BRASILEIRA
}

\author{
LAW 13.467 / 2017: ANALYSIS OF THE PRINCIPLE OF MINIMUM \\ INTERVENTION IN THE LIGHT OF THE ECONOMIC AND SOCIAL ORDER \\ OF THE BRAZILIAN CONSTITUTION
}

IVAN DIAS DA MOTTA ${ }^{1}$ ELIZABETH ACCIOLY RODRIGUES DA COSTA ${ }^{2}$ ROBERT THOMÉ NETO ${ }^{3}$

\section{RESUMO}

O presente trabalho analisa os efeitos decorrentes do Princípio da Intervenção Mínima, essência da Lei n. 13.467/2017 (Reforma Trabalhista), nos direitos trabalhistas fundamentados na ordem econômica e social, prescritas nos artigos 170 e 193, respectivamente, da Constituição brasileira. Assim, analisa de que modo o referido princípio está em consonância com o interesse coletivo e valores constitucionais de inclusão e sustentabilidade social. Para tanto, a estratégia teórica utilizada passa por uma investigação histórica acerca do desenvolvimento e evolução da concepção de Estado e a(s) consequência(s) de sua, necessária, função intervencionista. Para tanto, foi utilizado o método dedutivo-dialético, pelo qual se analisou textos constantes de livros, artigos e publicações jurídicas no geral, abordando o referido tema. Concluiu-se pela necessidade em se manter o papel intervencionista e regulador, assumido pelo Estado brasileiro, com a finalidade de assegurar e garantir cultura em torno do respeito aos fundamentos e princípios da ordem

\footnotetext{
${ }^{1}$ Possui graduação em Direito pela Universidade Estadual de Maringá (1996), mestrado em Direito das Relações Sociais pela Pontifícia Universidade Católica de São Paulo (1998) e doutorado em Direito das Relações Sociais pela Pontifícia Universidade Católica de São Paulo (2000), Pós-doutorado em Direito Educacional pela Pontifícia Universidade Católica de São Paulo (2001). Atualmente é professor permanente do Programa de Mestrado em Direito do Centro Universitário de Maringá, integrando a linha de pesquisa "A Tutela Constitucional e Privada dos Direitos da Personalidade nas Relações Privadas". Possui atuação profissional na área da advocacia e consultoria em Direito Educacional.

2 Graduada em Direito pela Faculdade de Direito de Curitiba, Diplomada em Estudos Europeus pelo Instituto Europeu da Faculdade de Direito da Universidade de Lisboa (1996), Doutora em Direito pela Universidade de São Paulo (2003), área de concentração em Direito Internacional. Atualmente é Professora do Curso de Direito da Universidade Europeia de Lisboa e Professora do Programa de Mestrado em Direito do Centro Universitário de Curtiba - UNICURITIBA. Atua na área de Direito Internacional Público, Direito da Integração, com ênfase no estudo da integração latino-americana, Direito da União Europeia, Direito Internacional Económico e Contencioso da União.Exerce a advocacia em Portugal e no Brasil

${ }^{3}$ Mestrando pelo Programa de Direito Empresarial e Cidadania; Pós-Graduando em Direito Tributário e Processo Tributário; Pós-Graduado em Direito Aduaneiro; Bacharel em Direito. Todas pela Faculdade de Direito de Curitiba (UNICURITIBA). Advogado. Sócio Fundador do escritório Basso, Boletta, Sureck \& Thomé Advocacia e Consultoria Jurídica; Membro do Grupo de Estudos igualdade, discriminação e trabalho no Unicuritiba e Membro da Comissão de Direito do Consumidor OAB-PR, 2019.
} 
econômica e da ordem social, na medida em que são objetivos, constitucionalmente positivados, da República Federativa do Brasil.

Palavras-chave: Estado; Social; Intervenção; Princípio; Necessidade.

\begin{abstract}
The present work analyzes the effects resulting from the Minimum Intervention Principle, the essence of Law no. 13,467 / 2017 (Labor Reform), in labor rights - as social rights - based on economic and social order, prescribed in articles 170 and 193, respectively, of the Brazilian Constitution. Thus, it analyzes how this principle is in line with the collective interest and principles of the economic order as constitutional values of inclusion and social sustainability. For that, the theoretical strategy used goes through a historical investigation about the development and evolution of the concept of State and the consequence (s) of its, necessary, interventionist function. For that, the deductive-dialectic method was used, by which texts from books, articles and legal publications in general were analyzed, addressing the referred theme. It was concluded that there is a need to maintain the interventionist and regulatory role, assumed by the Brazilian State, with the purpose of ensuring and guaranteeing culture around respect for the fundamentals and principles of the economic and social order, insofar as they are objective, constitutionally positive, from the Federative Republic of Brazil.
\end{abstract}

keywords: State; Social; Intervention; Principle; Need.

\title{
1. INTRODUÇÃO
}

O modelo de Estado Liberal, resultante da ascensão política da burguesia, organizou-se de maneira a ser o mais fraco possível, ou seja, um Estado mínimo, ao possuir funções restritas que beiram à mera vigilância em relação à ordem social.

Essa orientação política favoreceu a implantação e preservação da liberdade de comércio e de contrato, bem como a essência do caráter individualista da sociedade.

Portanto, o modelo liberal enfatizou a natureza egoísta humana, indo em descompasso à comportamentos associativos. Ainda, a concepção individualizada de liberdade impediu o Estado em proteger os menos afortunados, ocasionando crescente injustiça social.

Assim, após a Revolução Industrial na Europa nos séculos XVIII e XIX, se estimulou a manutenção de péssimas condições de trabalho e com ínfima remuneração. Consequência disso que nas primeiras décadas do século $\mathrm{XX}$ surgiram os primeiros movimentos socialistas com o objetivo de se conceber uma nova percepção do papel do Estado na sociedade. 
Essa nova concepção da função estatal buscava instrumentalizar, do plano teórico para o prático, valores fundamentais da pessoa humana, bem como a exigência de organização e funcionamento do Estado, em razão da proteção dos direitos naturais inerentes à pessoa humana.

Assim, sustentou-se por indispensável um sistema de controle social que assegurasse a igualdade de todos os indivíduos, ou seja, como valor supremo, na medida em que a liberdade, por sua vez, foi concebida tendo em vista o homem social, que inexistia isoladamente (DALLARI, 2001).

Com relação à Constituição de 1988, seus artigos 170 e 193 destacam, respectivamente, os princípios gerais da ordem econômica e da ordem social. Assim, necessária se faz, pois, uma interpretação dos referidos artigos em conjunto com o artigo $3^{\circ}$ da Constituição, ao qual explicita o projeto regente da República Federativa do Brasil.

Portanto, a Constituição brasileira caminha em direção contrária ao modelo do neoliberalismo, pois declara, prescritivamente, que o Estado brasileiro tem compromissos formalmente explicitados, obrigando que a ordem econômica e a social sejam articuladas de maneira a realizar os objetivos, tanto de patamares axiológicos como deontológicos, nela enunciados.

Assim, a valorização do trabalho humano, em razão do princípio da dignidade da pessoa humana, vetor axiológico prescrito na ordem econômica, sempre deve prevalecer como prioridade com relação ao interesse puramente econômico. Pois, a ordem econômica é, no direito brasileiro, intimamente harmonizada com a ordem social.

Por sua vez, a dicção prescrita no artigo 193 da Constituição é claríssima e torna indiscutível que para a Lei Magna, o objetivo primordial se faz nos moldes da justiça social, afastando-se, portanto, daquela prioridade de satisfação de interesses puramente de capital.

Sob essa premissa, a Consolidação das Leis do Trabalho (CLT) - consequência de longa jornada de conquistas de direitos trabalhistas que, em última análise, são expressões do Estado Social - representa mecanismo muito importante no resguardo da dignidade humana da pessoa trabalhadora e de patamares mínimos civilizatórios.

Nessa percepção que se sustentou necessária intervenção estatal nas relações trabalhistas, operando como contrapeso frente ao desequilíbrio existente no liame empregado-empregador. 
O Direito do Trabalho, dentre outras necessidades sociais, passou a atuar na subsistência do empregado por uma questão de dignidade da pessoa humana e valorização do trabalho humano. Nesse sentido, ocorre que a Lei 13.467/2017, popularmente conhecida como Reforma Trabalhista, alterou substancialmente a legislação laboral no Brasil.

Portanto, a maior preocupação posiciona-se em torno do embrião deontológico adotado pela referida lei. A essência da Reforma Trabalhista se consubstanciou no princípio da Intervenção Mínima do Estado. Ou seja, buscou enfraquecer e, até mesmo, afastar a função de regulador/fiscalizador (Estado-serviço) das relações trabalhistas.

Assim, alterou-se, na lei, profundamente as relações sociais de trabalho, sob a ótica não só da segurança, mas com relação ao meio ambiente e saúde do trabalho, pois se possibilitou legalizar aspectos contratuais, salariais e de condições de trabalho que, quando ocorriam, eram tomados como ilegais.

Uma vez que o modelo previsto pelo Constituinte de 1988 e assumido pelo Estado brasileiro, configura-se num viés de livre iniciativa, contudo, assentado no contexto do domínio social, significa dizer que embora seja inegável a necessidade de incentivo à econômica de mercado, isso não se deve em detrimento ao sufocamento dos direitos sociais. Situação essa, essência e objeto do Princípio da Intervenção Mínima abarcado pela Reforma Trabalhista.

Para tanto, o presente artigo buscará analisar de que modo o princípio da intervenção mínima está em consonância com o interesse coletivo e princípios da ordem econômica como valores constitucionais de inclusão e sustentabilidade social. Motivo pelo qual a presente pesquisa tem inconteste relevância social, ultrapassando a simples discussão acadêmica de um tema polêmico.

\section{ESTADO E FUNÇÃO SOCIAL}

A vida em sociedade traz evidentes benefícios ao homem, mas por outro lado, favorece a criação de uma série de limitações que, em certos momentos e em determinados lugares, são de tal modo numerosas e frequentes que chegam a afetar seriamente a própria liberdade humana (DALLARI, 2001). 
Fundamentalmente, há duas teorias que buscam explicar a origem da vida em sociedade. Por um lado, se defende que a sociedade é fruto de um fator natural, consequência da necessidade de que o homem tem na cooperação de seus semelhantes para a consecução dos fins de sua própria existência. Ou seja, o mesmo autor, a sociedade seria produto da conjugação de um simples impulso associativo natural da cooperação humana.

Por outro lado, os contratualistas sustentam que a sociedade é tão só, produto de um acordo de vontades, ou seja, de um contrato hipotético celebrado entre os homens. Assim, nega-se o fato de que a sociedade se originou em razão de uma premissa natural humana, uma vez que seu fundamento foi por meio da vontade (DALLARI, 2001).

Pode-se afirmar que atualmente predomina a ideia de que a sociedade não resulta tão somente de uma necessidade natural do homem, mas também, em razão da participação da consciência e vontade humana (DALLARI, 2001). Ou seja, a vida social é resultante de critérios de ordem natural e, também, material.

Portanto, necessário se faz assinalar que esta primeira conclusão deverá estar presente em todas as considerações sobre a vida social, sua organização com um centro de poder, sua dinâmica, seus objetivos e, especialmente, nas considerações sobre a posição e o comportamento do indivíduo na sociedade, pois, uma vez que esta é um imperativo natural, não se pode falar do homem concebendo-o como um ser isolado, mas sim, como homem social (DALLARI, 2001).

Por sua vez, a denominação 'Estado' (do latim statum), aparece pela primeira vez em 'O Príncipe', de Maquiavel, escrito em 1513. Embora muito antes, Políbio, no século II antes de Cristo, já estudava sobre as diferentes formas de governo (MIRANDA, 1996).

Para muitos, o Estado, assim como a própria sociedade, sempre existiu, pois desde que o homem vive sobre a Terra acha-se integrado numa organização social, dotada de poder e com autoridade para determinar o comportamento de todo o grupo.

Logo, sustentam que o Estado é considerado onipresente na sociedade humana (naturalmente ou espontaneamente), ao passo que é entendido como princípio organizador e unificador em toda organização social da humanidade (DALLARI, 2001).

Por outro lado, há autores quem entendem que a sociedade humana existiu, em sua origem e por certo período de tempo, sem a presença estatal. Assim, posteriormente, por motivos diversos, este foi constituído para atender às necessidades ou às 
conveniências perante cada grupo social. Ou seja, concebeu-se de maneira contratual, decorrência da vontade de alguns homens ou então de todos (DALLARRI, 2001).

Para, além disso, a ordem cronológica sustentada pela maioria dos estudiosos, com relação às formas fundamentais que o Estado adotou através dos séculos e em consequência dos respectivos contextos sociais, se configurou em: Estado Antigo, Estado Grego, Estado Romano, Estado Medieval e Estado Moderno. Cabe ao presente artigo, tratar essencialmente desse último (DALLARI, 2001).

No tocante ao conceito de Estado, importante frisar duas concepções fundamentais, sendo que suas diferenças se encontram no nível de ênfase que cada uma atribui aos elementos da 'força' e 'natureza jurídica' (DALLARI, 2001).

O Estado, enfatizado na noção de força, é visto, antes de tudo, como força que se põe a si própria. Ou seja, poder material irresistível, ou ainda, institucionalização/monopólio do poder, que por sua vez é limitado e regulado apenas pelo direito. (DALLARI, 2001), mormente porque não há Estado sem sujeição ao direito (MIRANDA, 1996).

Assim, todo Estado se funda na força. A violência não é, evidentemente, o único instrumento de que se vale, mas é seu instrumento específico. Ou seja, deve-se concebêlo como uma comunidade humana que, dentro dos limites de determinado território, reivindica o monopólio do uso legítimo da violência física.

Portanto, o Estado, cujo elemento enfático se faz na 'força', consiste em uma relação de dominação do homem sobre o homem, fundada no instrumento da violência legítima (WEBER, 2011).

Por outro lado, os fundamentos que se apoiam no viés jurídico não ignoram a presença da força. Entretanto, priorizam o elemento jurídico, ao passo que sustentam ser, o Estado, a unidade de um sistema jurídico que tem em si mesmo o próprio centro autônomo e que é possuidor da suprema qualidade de pessoa.

Em outras palavras, seria a corporação (no sentido de ordem jurídica) territorial dotada de um poder de mando originário. Logo, Estado como ordem coativa normativa da conduta humana. (DALLARI, 2001).

Com relação ao Estado Moderno, para, além disso, é possível identificar a existência permanente de quatro elementos materiais essenciais, sendo eles: soberania; território; povo e finalidade (MIRANDA, 1996). 
Em síntese, soberania está relacionada tanto à independência quanto ao poder jurídico soberano. Território está relacionado ao limite de espaço em que o poder da soberania será exercido. Povo exprime a ideia de um conjunto de indivíduos ou cidadãos que se unem para constituir o próprio Estado. Por fim, a finalidade norteia o conjunto de todas as condições de vida social que consintam e favoreçam o desenvolvimento integral da personalidade humana. (DALLARI, 2001).

O Conceito trazido por Dallari, além de incluir as orientações de 'força' e 'natureza jurídica', conseguiu abarcar todos os quatro elementos que integram o Estado Moderno, atualmente, uma vez compreendido como sendo a ordem jurídica soberana que tem por fim o bem comum de um povo situado em determinado território (DALLARI, 2001).

No referido conceito, a noção de 'poder' se encontra implícita na de soberania. E, no tocante ao 'bem comum' e 'território', ambos se enquadram como limitadores da ação jurídica e política do Estado.

O elemento da soberania, ao qual se representa pela força, deve ser entendido como sendo do Estado como entidade jurídica global e complexa, e não de seus órgãos e titulares. A soberania surge como um feixe de faculdades ou direitos que o Estado exerce relativamente a todos os indivíduos e a todas as pessoas, coletivamente. A regulamentação dessas pessoas, a atribuição da capacidade de direitos, a imposição de deveres e de sujeições, eis então algumas das manifestações do poder (MIRANDA, 1996).

Importante observar que o Estado moderno nasceu absolutista e durante alguns séculos todos os defeitos e virtudes do monarca absoluto foram confundidos com as qualidades do Estado. Isso porque no século XVIII o poder público era visto como inimigo da liberdade individual e qualquer restrição ao individual em favor do coletivo era tida como ilegítima. Essa foi a raiz individualista do Estado Liberal. (DALLARI, 2001).

Stuart Mill apresenta três objeções fundamentais à interferência do Estado na sociedade: a) ninguém é mais capaz de realizar qualquer negócio ou determinar como ou por que deva ser realizado do que aquele que está diretamente interessado. Assim é provável que os indivíduos façam melhor do que o Estado; b) mesmo que os indivíduos não realizem tão bem o que se tem em vista, como o faria o Estado, é melhor ainda que o 
próprio indivíduo o faça e c) norteia a ideia de grande mal em acrescentar ao Estado o poder sem necessidade.

Assim, o Estado Liberal, resultante da ascensão política da burguesia, organizouse de maneira a ser o mais fraco possível, caracterizando-se como o Estado mínimo, possuindo funções restritas, quase que à mera vigilância (Estado-polícia) da ordem social (DALLARI, 2001).

Estado Liberal, portanto, assente na ideia de liberdade e, em nome dela, empenhado em limitar o poder político tanto internamente (divisão) como externamente, pela redução ao patamar mínimo das suas funções perante a sociedade. (MIRANDA, 2005).

Essa orientação política favoreceu a implantação e preservação da liberdade de comércio e da liberdade de contrato, bem como da essência do caráter basicamente individualista da sociedade.

Por um lado, essa concepção de Estado com um mínimo de interferência na vida social, trouxe, inicialmente, inegáveis benefícios com relação ao progresso econômico acentuado, a valorização do indivíduo e o desenvolvendo da consciência da importância da liberdade humana.

Entretanto, o modelo liberal criou as condições para sua própria superação (DALLARI, 2001). Em primeiro lugar a valorização do indivíduo chegou ao ultra individualismo, pois ignorou a natureza associativa do homem e deu margem a um comportamento egoísta. Ao lado disso, a concepção individualista da liberdade impediu o Estado em proteger os menos afortunados, causando uma crescente injustiça social, na medida em que se concedeu a todos o direito de ser livre, porém não se assegurava a ninguém o poder de ser livre.

Assim, após a Revolução Industrial do século XIX e início do XIX, revelou-se grande exploração das pessoas hipossuficiente (vulnerável) por aqueles que detinham o poder econômico e os meios de produção. A era da industrialização nasceu de forma agressiva aos direitos fundamentais da pessoa humana, uma vez que era o mercado, portanto, quem ditava as regras de produção.

A ideia essencial se ajustava na minimização dos gastos para gerar maximização dos lucros. Portanto, prevalecia a lei do mercado onde era o empregador quem ditava as regras, sem intervenção do Estado - liberdade contratual. A jornada era de até 16 horas e a exploração de mão-de-obra infantil chegou a níveis alarmantes. (CASSAR, 2014). 
Consequentemente, a formação do proletariado, sendo grandes aglomerados urbanos, ao passo da excessiva existência de mão-de-obra. Estimulava-se a manutenção de péssimas condições de trabalho e com ínfima remuneração. (DALLARI, 2001).

Foi com base nessa tangenciada contextualização que se estimularam, no século XIX, os movimentos socialistas e, nas primeiras décadas do século XX, uma ideologia intervencionista a fim de conceber uma nova compreensão do papel do Estado na sociedade.

A nova concepção da função estatal buscava instrumentalizar, do plano teórico para o prático, certos valores fundamentais da pessoa humana, bem como a exigência de organização e funcionamento do Estado, em razão da proteção dos direitos naturais inerentes à pessoa humana.

Esse discurso da dignidade da pessoa humana nas relações de trabalho não é retórica, veja-se que naquele período da revolução industrial, o trabalhador, na sua dignidade fundamental de pessoa humana, não interessava/preocupava os chefes industriais daquele período (VIANNA, 1997).

Assim, sustentou-se que o Estado (e o Direito) teria papel crucial nas constantes crises do capitalismo, no sentido de modificar alguns de seus aspectos, mas mantendo sua essência. Ou seja, regenerar permanentemente o capitalismo, o que implicaria transformações no campo jurídico e político (CALDAS, 2014).

Assim, sustentou-se por indispensável um sistema de controle social que assegurasse a igualdade de todos os indivíduos, ou seja, como valor supremo, na medida em que a liberdade, por sua vez, foi concebida tendo em vista o homem social, que não deveria existir de maneira isolada (DALLARI, 2001).

A liberdade humana, portanto, é social (situada), que deve ser concebida em razão do relacionamento coletivo, de cada indivíduo com todos os demais, implicando deveres e responsabilidades. A concepção individualista da sociedade, ignorando o homem como ser social, foi fundamentalmente egoísta, pois desligou o indivíduo de compromissos sociais e, por isso mesmo, deu margem a mais desenfreada exploração do homem pelo próprio homem. (DALLARI, 2001).

\section{O DOMÍNIO ECONÔMICO E SOCIAL NA CONSTITUIÇÃO DE 1988}


A progressão constitucional brasileira, seguiu, em linhas gerais, as diretrizes jurídicas e políticas do Estado individualista-liberal, no que diz respeito à ordem econômica. A própria Carta Imperial de 1824 até a Constituição vigente é constante e de relevo inegável, a filosofia do liberalismo econômico (MARINHO, 2011).

A Constituição de 1824, por ser um postulado do liberalismo político e econômico, não continha capítulo sobre a ordem econômica ou social. Encontravam-se algumas normas de natureza econômica dispersas no título das garantias dos direitos civis e políticos.

A Constituição de 1891 sobrevêm no mesmo quadro de acatamento aos valores tradicionais da ordem econômica e social. Assim, manteve-se a fisionomia do regime liberal, no domínio político e no econômico-social, inspirando-se no modelo americano de 1787 (MARINHO, 2011). Entretanto nada se dispunha com relação ao trabalho e a situação dos assalariados.

Com a forte influência da Constituição alemã de 1919, a Constituição política de 1934, trouxe certa inovação, embora adstrita à essência do regime individualista-liberal. Disciplinou, em título próprio, no artigo 115, a ordem econômica e social, entretanto, não restou proclamado sua natureza deontológica, ou seja, não detinham caráter de princípio (MARINHO, 2011).

Nasceram, também, as cláusulas protetoras do trabalho e do trabalhador, nos artigos 120 a 122. Compreendiam e garantia de reconhecimento dos sindicatos e das associações profissionais; a enumeração dos direitos fundamentais do assalariado e a institucionalização da Justiça do Trabalho, como organismo competente para dirimir questões entre empregadores e empregados (MARINHO, 2011).

Segundo o mesmo autor, essas e outras regras configuraram importante núcleo de uma política de planificação, de economia supervisionada e de justiça social, redutora de abusos do individualismo capitalista (MARINHO, 2011).

Por sua vez, a Constituição de 1946, numa época de pós-guerra, organizou-se conforme os princípios da justiça social, ao passo que conciliou a liberdade de iniciativa com a valorização do trabalho humano, reconhecendo, portanto, os direitos do trabalhador em seus artigos 145 e 157. Assim, a Justiça do Trabalho foi situada no sistema do Poder Judiciário, conferindo a seus membros maiores garantias para decidir soberanamente os conflitos entre o capital e o trabalho (MARINHO, 2011). 
Com relação à Constituição de 1967 foi incluído, no artigo 160, a liberdade de iniciativa dentre os princípios informadores da ordem econômica e social, limitando o poder da intervenção estatal no domínio econômico.

Portanto, esse viés intervencionista, que buscou moderar os excessos do capitalismo, foram fórmulas tecnocráticas e neocapitalistas que não suprimiram as bases da ordem econômica individualista, fundada no poder privado de domínio dos meios de produção e dos lucros respectivos (MARINHO, 2011).

É evidente que as constituições brasileiras de 1824 a 1967 se filiaram ao regime individualista. Mas foi partir de 1934, principalmente, que se verifica a forte influência do pensamento intervencionista ou socializante (MARINHO 2011).

Com relação à Constituição de 1988, seus artigos 170 e 193 destacam, respectivamente, os princípios gerais da ordem econômica e da ordem social. Pelo primeiro temos que "a ordem econômica, fundada na valorização do trabalho humano e na livre iniciativa, tem por fim assegurar a todos existência digna, conforme os ditames da justiça social, observados os seguintes princípios [...]". Enquanto que o artigo 193 prescreve que "a ordem social tem como base o primado do trabalho, e como objetivo o bem-estar e a justiça sociais".

Os referidos artigos, 170 e 193, devem ser interpretados em conjunto com o artigo $3^{\circ}$ da Constituição, ao qual a Lei Magna faz uma explícita proclamação do projeto regente da República Federativa do Brasil. Ou seja, proclama o referido artigo que constitui objetivo fundamental: construir uma sociedade livre, justa e solidária; garantir o desenvolvimento nacional; erradicar a pobreza e reduzir as desigualdades sociais, de forma a promover o bem de todos (DE MELLO, 2019).

Nota-se que a preocupação com relação ao comprometimento da justiça social foi tamanha que o referido valor apresentou-se positivado como princípio tanto da ordem econômica quando da ordem social.

Portanto, a Constituição brasileira de 1988 estampa-se como antítese ao modelo neoliberal, pois declara, prescritivamente, que o Estado brasileiro tem compromissos formalmente explicitados, obrigando que a ordem econômica e a social sejam articuladas de maneira a realizar aqueles objetivos axiológicos nela enunciados (DE MELLO, 2019).

Entretanto, para o referido autor, e, sob pena de nulidade, em todos os casos em que a lei assegura a interferência estatal na atividade econômica, deverá estar volvida à 
satisfação daqueles fins dantes aludidos, pois jamais poderá expressar tendência ou diretriz antinômica ou gravosa àqueles valores constitucionais.

Assim, a valorização do trabalho humano, por ser princípio prescrito da ordem econômica, sempre deve prevalecer como prioridade em relação ao interesse puramente econômico. Pois, a ordem econômica é, no direito brasileiro, intimamente entrosado com a ordem social.

Em outras palavras: a ordem econômica necessita, para estrito cumprimento da Constituição, orientar-se de modo a atender os princípios e objetivos aludidos na ordem social.

Por sua vez, a dicção prescrita no artigo 193 da Constituição é claríssima e torna indiscutível que, para a Lei Magna, o objetivo primordial se faz nos moldes da justiça social, afastando-se, novamente, daquela prioridade da satisfação de interesses puramente de capital.

Assim, uma vez que tanto a ordem social como o próprio domínio econômico indicam como um de seus fundamentos à valorização do trabalho humano, orienta-se a ideia de que existe um projeto no qual foi cometida, ao Estado, a função de protagonista necessário de implementação destes bens jurídicos.

Há um programa constitucional em que está luminosamente explicita a propriedade ao que seja favorecedor do trabalho e dos trabalhadores, relegando-se a segundo plano o que favoreça ao capital e aos interesses dos capitalistas. Isso não significa menoscabar seja a importância, seja a valia desta segunda ordem, mas significa que a realização deles há de estar entrosada com a realização dos primeiros (DE MELLO, 2019).

Consequência disso, o Estado não poderia estacionar na concepção puramente de 'vigia', mas adotar, progressivamente, papel social, ou seja, um Estado de serviço, pois, a liberdade humana, e, para todos os efeitos, social.

\section{O PRINCÍPIO DA INTERVENÇÃO MÍNIMA A PARTIR DA LEI 13.467/2017 (REFORMA TRABALHISTA)}

Sob essa premissa, a Consolidação das Leis do Trabalho (CLT) - consequência de longa jornada de conquistas de direitos trabalhistas que, em última análise, são 
expressões desse Estado Social - representa mecanismo muito importante no resguardo da dignidade humana da pessoa trabalhadora e de patamares mínimos civilizatórios.

Igualmente, a pressão das lutas sindicais, ao longo dos séculos XIX e XX, que pressionaram a criação de regulamentações ao labor, sobretudo aquelas vinculadas à valorização do trabalho humano, além do respeito à cidadania.

As conquistas dos direitos trabalhistas, tais como temos hoje, concretizaram-se, somente, em razão da função reguladora do Estado. Ou seja, somente com a fixação da legislação trabalhista, como estrutura jurídica normativa, desenvolveu-se cultura em torno do respeito a determinadas condições de trabalho, ante a força e poder fiscalizatório desse Estado-Serviço.

Logo, a percepção estritamente econômica do contrato individual de trabalho abriu margem à garantia da proximidade com a justiça social, na medida em que se destacaram valores sociais do trabalho em razão da dignidade da pessoa humana patamar axiológico supremo.

Em outros termos, ambas as partes assumem responsabilidades que refletem, além daquelas de cunho pecuniário, de proporcionar ao empregado ambiente; condições; saúde e segurança do trabalho, na medida em que ambas envolvem terceiros interessados - a sociedade como um todo.

É nessa percepção que se sustentou a necessária intervenção estatal nas relações trabalhistas, operando como contrapeso frente ao desequilíbrio existente no liame empregado-empregador. O constituinte privilegiou o modelo capitalista, contudo garantiu a finalidade da ordem econômica, ao assegurar a todos existência digna, conforme os ditames da justiça social. Portanto, afastando-se de um modelo de Estado vigia, absenteísta (LENZA, 2011).

Assim, para a tutela dos direitos trabalhistas a fim de garantir-lhes proteção em um cenário desfavorável e desproporcional, faz-se necessária à presença estatal por intermédio do Poder Judiciário, na medida em que se depara com a realidade posta e não com aquela realidade pressuposta textualizada na letra da lei (MARTINS; GUNTHER E VILLATORE, 2019).

Para tanto, o Direito do Trabalho, em última análise, atua na subsistência do empregado por uma questão de dignidade da pessoa humana, valorização do trabalho humano, dentre outros princípios e razões que, igualmente, estão previstos nos laços do domínio econômico e social da Constituição. 
Nesse sentido, a Lei 13.467/2017, denominada de Reforma Trabalhista, alterou substancialmente a CLT no Brasil. Sua principal motivação não foi jurídica, vez que seu viés econômico se sobrepôs ao direito.

Nessa perspectiva, persiste ao que se observa, a dúvida quanto à vinculação entre direito e economia, Martins, de maneira que as garantias constitucionais devem ser vistas e interpretadas de forma impositiva e que em relação a elas, interesses que não corroborem para a sua efetivação, devem ser rechaçados, o que inclui pretensão normativa de cunho econômico tendenciosa a suprimir, sobretudo, direitos sociais assegurados na Constituição de 1988, e, nesse particular, trabalhistas (MARTINS; GUNTHER E VILLATORE, 2019).

Para além do universo prático, contudo, a maior preocupação se funda em torno do embrião deontológico adotado pela Lei 13.467/2017. A essência da Reforma Trabalhista consubstanciou-se no princípio da intervenção mínima do Estado. Ou seja, buscou enfraquecer e, até mesmo, afastar a função de regulador/fiscalizador, do Estadoserviço, e, redefini-lo para aquele modelo anterior, na concepção de Estado vigia, absenteísta.

Assim, alterou-se profundamente as relações sociais de trabalho, sob a ótica não só da segurança, mas com relação ao meio ambiente e saúde do trabalho, pois se possibilitou legalizar aspectos contratuais, salariais e de condições de trabalho que, quando ocorriam, eram tomados como ilegais.

Em síntese, a receita da reforma trabalhista priorizou, como ingrediente principal, a intervenção mínima. Nessa ótica, quando se defende que o acordado vale mais que o legislado, colocam-se em pé de igualdade, para livre negociação, dois polos aos quais a história já demonstrou serem desiguais.

O referido princípio está positivado no artigo $8^{\circ}, \S 3^{\circ}$, segunda parte, da CLT, ao estipular que: “A Justiça do Trabalho [...] balizará sua atuação pelo princípio da intervenção mínima na autonomia da vontade coletiva".

Dentre outros, é possível identificar seus reflexos nos artigos 444 e 611-A da CLT, ao qual elencaram as possibilidades em que o negociado se sobrepõe ao legislado. Denota-se que os referidos artigos estão, portanto, assentados na ideia de "última ratio" da atuação estatal nas relações trabalhistas.

Assim, a Consolidação das Leis do Trabalho pós-reforma, busca proibir que o Judiciário se manifeste sobre cláusulas desvirtuadas da legislação social, uma vez que os 
princípios, e nesse caso o da intervenção mínima, detém função informadora, servindo de diretriz ao legislador.

O Princípio da intervenção mínima tem fundamento teórico e jurídico no ordenamento jurídico brasileiro, em um particular subsistema da estrutura normativa, no Direito Penal, ao qual decorre de uma via intermediária oriundo do movimento do direito penal mínimo (DOTTI, 2018).

Portanto, no viés legalista e normativo, o referido princípio fundamenta-se e adequa-se às novas relações que se estabelecem e isso se explica pela menor intervenção do Estado nas relações humanas. (MARTINS; GUNTHER; VILATORE, 2019, p. 162).

Contudo, vale lembrar que a Constituição de 1988, no caput de seu artigo $7^{\circ}$ (Brasil, 1988), indica que o rol de direitos trabalhistas é assegurado, sem prejuízo de outros que visem melhorar a condição social dos trabalhadores. Significa dizer que há um contrato mínimo a ser venerado, de maneira que esvaziá-lo, por iniciativa do Poder Legislativo, ao intervir com lei que, por sua vez, abarca o preceito da intervenção mínima, veio a ferir, inclusive, a própria Constituição de 1988.

Portanto, uma vez que o modelo previsto pelo Constituinte de 1988 e assumido pelo Estado brasileiro, configura-se num viés de livre iniciativa, contudo, assentada no contexto do domínio social, significa dizer que embora seja inegável a necessidade de incentivo à econômica de mercado, isso não se deve em detrimento ao sufocamento dos direitos sociais. Situação essa, perceptível no princípio da intervenção mínima abarcado pela Reforma Trabalhista.

\section{INCLUSÃO E SUSTENTABILIDADE COMO VALORES CONSTITUCIONAIS DA JUSTIÇA SOCIAL.}

No plano nacional, a Constituição de 1988, em seu capítulo II, intitulado: “Dos Direitos Sociais", dispõe em seu artigo $6^{\circ}$, entre outros, que são direitos sociais o trabalho na forma da Constituição. Ainda, no artigo $7^{\circ}$, prevê os direitos dos trabalhadores, além de outros, que visem à melhoria de sua condição social (MARTINS; GUNTHER E VILATORE, 2019, p. 34). 
A Constituição de 1988 supervalorizou o ser humano. Para tanto, o constituinte manifestou seu desejo de alterar o eixo de prioridade, passando do Estado para o próprio homem (LIMA, 2013).

Assim, a atenção passa a ser com maior intensidade ao indivíduo e não tanto para o Estado. Contudo, não significa que se está a proteger somente o trabalhador, mas a todos os indivíduos, portanto, quanto se refere aos Direitos Sociais.

Nas palavras de Lima (2013, p. 40):

Daí inferir-se que a expressão Direitos Sociais extravasa dos direitos do trabalhador (ex.: direito à moradia, à saúde, à educação etc.). Enquanto os direitos de liberdade correspondem ao primeiro postulado da Revolução Francesa, os sociais ligam-se ao segundo - igualdade. Pelos primeiros, a pessoa exige que o Estado abstenha-se de interferir, salvo para assegurar o exercício do direito; no segundo, a pessoa exige intervenção do Estado, no sentido de assegurar-lhe vida digna.

Para tanto, a Justiça do Trabalho, por ser expressão do Estado Social, busca tutelar os direitos trabalhistas a fim de garantir-lhes proteção em face de um cenário desfavorável e desproporcional, uma vez que a intervenção estatal por intermédio do Poder Judiciário se mostra necessária, ao passo que se depara com a realidade posta e não com aquela realidade pressuposta e textualizada na letra da lei (MARTINS; GUNTHER E VILATORE, 2019, 144).

$\mathrm{O}$ acesso à justiça aos tribunais já foi considerado como concretização do princípio estruturante do estado de direito. Portanto, a estrutura normativa constitucional brasileira não destoa dessa premissa, ao passo que possui compromissos internos e externos, com outras plataformas de Direito vinculando-se, portanto, ao plano internacional à tutela a essa garantia constitucional (CANOTILHO, 2003).

Assim, a garantia ao acesso à justiça em plano interno, não é uma característica de Estado paternalista, mas de um modelo estatal que, além de respeitar e fazer valer suas regras constitucionais, também é indissociável o ideal de garantir o acesso à justiça. Portanto, um estado democrático de direito.

Nesse sentido, a Constituição de 1988, ao tutelar fortemente a justiça social, que, por sua vez, abraça em si os domínios econômico e social, o faz justamente para evitar que ocorra afronta ao bem da vida protegido constitucionalmente. A justiça, portanto, é 
uma condição da existência objetiva, o fundamento necessário do pacto social, ao qual decorrem, a ordem econômica e a ordem social, sendo elas inseparáveis.

Logo, o modelo de Estado assumido pelo constituinte de 1988, e ainda em vigor, encontra-se em uma medida de alternância entre a livre iniciativa e social. Entretanto, não significa dizer que ocorra o sufocamento de um em favor do outro, na medida em que a ordem econômica e a ordem social, para além de compartilharem de um mesmo princípio - justiça social - devem ser interpretados em conjunto com o artigo $3^{\circ}$ da Constituição, ao qual explicita a proclamação do projeto regente da República Federativa do Brasil.

Frisa-se, a preocupação com relação ao empenho da justiça social, foi tamanha, que fez com que ela comparecesse, em caráter axiológico e deontológico, tanto na ordem econômica quanto da ordem social e, portanto, indissociáveis.

Nas palavras de Martins; Gunther; Vilatore (2019, p. 165)

O direito do trabalho, enquanto constitucionalmente previsto como direitos sociais (art. $6^{\circ}, 7^{\circ}$ e $8^{\circ}, \mathrm{CF} / 88$ ) (BRASIL, 1988), não encontra impedimento ao acesso à justiça, portanto, importar o princípio da intervenção mínima aplicável ao direito penal para o direito do trabalho trata-se de retrocesso social e violação a um princípio macro da Constituição de 1988, acesso à justiça.

Nessa leitura, a previsão normativa do princípio da intervenção mínima buscou inaugurar o movimento do direito do trabalho mínimo, o que significa tutela mínima a direitos sociais e, assim, inaplicável ao direito do trabalho vez que se revela, portanto, inconstitucional e em dissonância com o interesse coletivo e princípios da ordem econômica como valores constitucionais de inclusão e sustentabilidade social.

\section{CONSIDERAÇÕES FINAIS}

Uma vez sendo o direito do trabalho, valor social, garantido e prescrito constitucionalmente, exige uma prestação e intervenção positiva do Estado, ou seja, de um modelo de Estado-serviço em que os direitos sociais devem ou deveriam estar intrinsecamente conectados às possibilidades de o Estado em efetivá-los. 
A valorização do trabalho humano, por ser princípio prescrito da ordem econômica em razão da dignidade da pessoa humana, sempre deve prevalecer como prioridade em relação ao interesse puramente econômico. Pois, a ordem econômica é, no Direito brasileiro, intimamente relacionada com a ordem social.

Evidente que toda ordem econômica necessita, para cumprimento da Constituição, orientar-se de modo a atender os princípios e objetivos da ordem social. Logo, implica dizer que são inconstitucionais quaisquer medidas econômicas tomadas pelo Estado em descompasso com estes rumos ou capazes de afetá-los.

Nesse sentido, a reforma trabalhista, ao flexibilizar e restringir direitos trabalhistas, e, portanto, sociais, desconsiderou que a Constituição de 1988 é dirigente. Ou seja, demonstrou não guardar compatibilidade com a característica de que tanto a ordem econômica quanto a ordem social respaldam-se e orientam-se, sobretudo, numa característica comum, a justiça social.

A Lei 13.467/2017, ao alterar substancialmente a CLT, teve, sem sombra de dúvidas, como principal motivação, viés econômico, que, portanto, se sobrepôs ao direito.

Assim, a previsão normativa do princípio da intervenção mínima buscou inaugurar certo movimento do direito do trabalho mínimo. Assim, deveria, pois, ser inaplicável ao direito do trabalho, ante sua incompatibilidade frente aos fundamentos e princípios constitucionais constantes no domínio econômico e domínio social que, portanto, regem-se sob a ótica deontológica da justiça social, e, esta como sendo o patamar axiológico supremo do Título II, Capítulo II da Constituição de 1988 - "Dos Direitos Sociais".

\section{REFERÊNCIAS}

BORGES, Alexandre Walmott et al. A violação à ordem econômica na constituição de 1988 e à lei antitruste no exercício disfuncional da ação na defesa da propriedade intelectual. Revista Jurídica, [S.1.], v. 2, n. 47, p. 335-362, jul. 2017. ISSN 2316-753X. Disponível em:

$<$ http://revista.unicuritiba.edu.br/index.php/RevJur/article/view/2038/1317〉. Acesso em: 14 abr. 2020. doi:http://dx.doi.org/10.21902/revistajur.2316-753X.v2i47.2038. 
BRASIL. Constituição da República Federativa do Brasil de 1988. Disponível em: <http://www.planalto.gov.br/ccivil_03/constituicao/constituicao.htm>. Acesso em 10 de abril de 2019.

BRASIL. Lei $\mathbf{n}^{\mathbf{0}}$ 13.467, de 13 de julho de 2017 (Lei da Reforma Trabalhista). Disponível em: <http://www.planalto.gov.br/ccivil_03/_ato20152018/2017/lei/l13467.htm>. Acesso em 10 de abril de 2019.

CALDAS, Camilo Onoda. O Estado; organizadores Marcelo Semer, Marcio Sotelo Felippe. $1^{\text {a }}$ ed. São Paulo, Estúdio Editores.com, 2014.

CANOtilho, J.J. Gomes. Direito Constitucional e Teoria da Constituição. $3^{\text {a }}$ ed. Coimbra: Almedina, 1988.

CASSAR, Vólia Bomfim. Direito do Trabalho. Rio de Janeiro, $3^{\text {a }}$ ed. Impitus, 2014.

DALLARI, Dalmo de Abreu. Elementos de Teoria Geral do Estado. 22a ed. São Paulo, Saraiva, 2001.

DE MELlo, Celso Antônio. Curso de Direito Administrativo. 34 a ed. São Paulo: Malheiros, 2019.

LENZA, Pedro. Direito Constitucional Esquematizado. 15. ed. São Paulo: Saraiva, 2011.

MARINHO, Josaphat. A Ordem Econômica nas Constituições Brasileiras. Direito Constitucional. Constituição Financeira Econômica e Social. São Paulo: vol. 6, n. 0549, revista dos tribunais, 2011.

MARTINS, Gustavo Afonso; GUNTHER, Luiz Eduardo; VILLATORE, Marco Antônio César. O Princípio da Intervenção Mínima e o Acesso à Justiça do Trabalho. Curitiba: Instituto Memória. Centro de Estudos da Contemporaneidade, 2019.

MIRANDA, Jorge. Ciência Política: formas de governo. Lisboa, Rio de Mouro, 1996. 
MIRANDA, Jorge. Teoria do Estado e da Constituição. Rio de Janeiro, 2005.

SILVA, Homero Batista Mateus da. Comentários à reforma Trabalhista, análise da lei 13.467/2017. São Paulo: Revista dos Tribunais, 2017.

SÜSSEKIND, Arnaldo; MARANHÃO, Délio; VIANNA, Segadas; TEIXEIRA, Lima. Instituições de Direito do Trabalho. 17. ed. São Paulo: LTr, 1997, v. 1.

WEBER, Max. Ciência e Política: dias vocações. $18^{\mathrm{a}}$ ed. São Paulo, Pensamento Cultrix, 2011. 